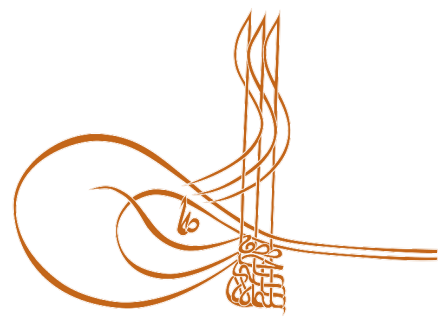

www.turkishstudies.net/language
Turkish Studies - Language and Literature

eISSN: $2667-5641$

Research Article / Araştırma Makalesi

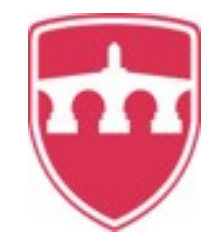

INTERNATIONAL

BALKAN

UNIVERSITY

Sponsored by IBU

\title{
Türk Edebiyatı Öğretiminde Geleneksel Hikâye Anlatıcılığından Medyatik Hikâye Anlatıcılığına: Heredot Cevdet
}

\author{
From Traditional to Mediatic Storytelling in Teaching of Turkish Literature: Heredot Cevdet
}

\author{
Yasemin Uzun $^{*}$ - Zeynep Türksever ${ }^{* *}$
}

\begin{abstract}
Literary genres have also differentiated with the becoming popular of the media. Books have been read electronically, the letter was replaced by an electronic letter. Some literary genres have also been fupdated with the use of media. While the literary books are transferred to the series, they appear with images in today's world. Meddah, which is a literary genre, started to enter our lives with different types of media. Meddah appears sometimes as theater, sometimes as stand up and sometimes as episodes in the series. Heredot Cevdet is one of these examples. In this study, Heredot Cevdet narratives in Ekmek Teknesi series are discussed in the context of meddah. The series Ekmek Teknesi was televised in 2002-2005 in three seasons and one hundred and six episodes. The character of Heredot Cevdet is an updated interpretation of the traditional narrative tradition of meddah in the electronic culture. In each episode of the series, Heredot Cevdet usually tells a story to the audience in genres such as folk story, epic, autobiographical story and historical story. In this study, Heredot Cevdet narratives around the concept of meddah and using of these narratives in Turkish literature education were examined. The research was prepared by document analysis which is one of the qualitative research methods. Twelve episodes were identified in line with the content of this research: Leyla ile Mecnun (chapter 4), Köktürk Yazıtları (chapter 6), Ferhat ile Şirin (chapter 19), Evliya Çelebi (chapter 22), Çanakkale Şehitleri'ne (chapter 25), Yusuf ile Züleyha (chapter 28), Bülbülün Așkı (chapter 31), Kerem ile Aslı (chapter 48), Mehmetoğlu Mehmet (chapter 53), Kırklar Dağı ve Suzan Suzi (chapter 54), Oğuz Kağan Destanı (chapter 79), T1kandı Baba (chapter 104). The narratives in these sections were examined in comparison with the meddah characteristics. Then, using of these narratives in teaching of Turkish literature was evaluated.
\end{abstract}

\footnotetext{
* Dr. Öğr. Üyesi, Çanakkale Onsekiz Mart Üniversitesi, Eğitim Fakültesi, Türkçe ve Sosyal Bilimler Eğitimi, Türk Dili ve Edebiyatı

Assist. Prof. Dr., Canakkale Onsekiz Mart University, Education Faculty, Turkish and Social Science Education, Turkish

Language and Literature

ORCID 0000-0001-8995-772X

yaseminuzun@hotmail.com

${ }_{* *}^{*}$ Uzm, Milli Eğitim Bakanlığı, İstanbul.

Specialist, Ministry of National Education, Istanbul

ORCID 0000-0002-4569-2288

z.turksever@windowslive.com
}

Cite as/ Atıf: Uzun, Y. \& Türksever, Z. (2020). Türk edebiyatı öğretiminde geleneksel hikâye anlatıcıllı̆ından medyatik hikâye anlatıcılı̆̆ına: Heredot Cevdet, Turkish Studies - Language, 15(1), 477-496. https://dx.doi.org/10.29228/TurkishStudies.40302

Received/Geliş: 25 December/Aralık 2019

Accepted/Kabul: 21 March/Mart 2020

Copyright (C) INTAC LTD, Turkey 
Structured Abstract: Introduction: Meddahlık (eulogy show in ottoman culture and entertainment life) has been effective in Turkish society for many years. Encomiastic, which aims to inform people while entertaining, has continued until the 20th century in its traditional form. According to Jacob, encomiastic is a speech artist whose job is to tell a story. (Nutku, 2006, p. 44).

Before the encomiastics, there is a tradition of story telling in Turkish culture. The tradition of storytelling in Turkish culture started with shamans and continued with bards, minstrels and encomiastic (Boratav, 2002, p. 85).

From the 20th century onwards, the traditional encomiastic used in coffeehouses was finished and the tradition began to be seen either in the theater or the media.

This encomiastic appearance in the theater is sometimes seen in the media. These narratives that appear in the media can be considered as the secondary verbal culture product proposed by Ong (2003). Heredot Cevdet character in the Ekmek Teknesi series, which was televised in a total of one hundred and six episodes between 2002 and 2005, is an updated interpretation of encomiastic in electronic culture. In each episode of the series, Heredot Cevdet tells a story. Folk tales, epics, autobiographical stories, historical stories are narrative types in these series.

In this study, the tradition of encomiastic will be evaluated with Heredot Cevdet character and how these narratives can be used in teaching of Turkish Literature will be determined. There are only twelve stories that can be used in teaching of Turkish literature. Other narratives are not in the scope of Turkish literature, so they are not included in the study.

\section{Method}

The research was prepared by document analysis which is one of the qualitative research methods. Twelve episodes were identified in line with the content of this research: Leyla and Mecnun (chapter 4), Köktürk Yazıtları (chapter 6), Ferhat and Şirin (chapter 19), Evliya Çelebi (chapter 22), Çanakkale Şehitleri'ne (Chapter 25), Yusuf and Züleyha (Chapter 28), Bülbülün Aşk1 (Chapter 31), Kerem and Aslı (Chapter 48), Mehmetoğlu Mehmet (Chapter 53), Kırklar Dağ1 and Suzan Suzi (Chapter 54) Epic of Oguz Kagan (79th episode), Tikandı Baba (104th episode).

\section{Findings}

Heredot Cevdet in the series Ekmek Teknesi is a performer of narratives and is known and respected by everyone. It emerges as a mixture of the historian Herodotus and Ahmet Cevdet Pasha, known for his synthesis. This feature also facilitates its credibility.

The fact that the place in the narratives is a coffeehouse and the time is evening hours is similar to the traditional encomiastic.

The accessories of the encomiastic are usually chairs, walking sticks or sticks, handkerchiefs or macramas. When Herodotus Cevdet enters the coffeehouse, he sits on the chair. For the sake of attention, he hits the glass of tea three times on the table. This acts as a stick in the narrative.

When the narratives are examined in terms of language and style, it is seen that the rhymes, reduplication, rhetoric, imitations and analogies used by the encomiastic when telling stories are also used in Heredot Cevdet.

Heredot Cevdet gives the clues about the narrative in the beginning.

Dream, being separated from each other, magic, mountain, number 40, childlessness, votive, lovers of different religions; number 40, gold and silver, arrow and bow, sky, mountain and sea, day, moon and star, sky feathered, sky mane wolf, light and the more sacred east of the west in Oğuz Kağan Epic are the motifs and mythological elementsv in these tellings.

There are examples of Turkish traditions and customs in the narratives. Current features in narratives are often used with the laughing function and there are updated elements: Filling Evliya Çelebi's suitcase with comb, toothbrush, shaver, blue card, insurance policy, school diplomas and her favorite teddy bear into a backpack and taking a tape recorder from the free shop. In the story of Kerem and Asli, the lovers communicate each other by mail, email or courier; The story of Sultan II. Mahmud, he took off the Superman clothes and entered into the public by wearing Clark Kent clothes. 
At the end of the performance of encomiastic, an advice is given.

\section{Results}

The characteristics of Heredot Cevdet narratives can be evaluated as an updated expression of traditional encomiastic as seen in the media. From this perspective, narratives can also be used in the education.

The Turkish Language and Literature curriculum includes the following achievements in theatrical genre:

"Determines the the type of text and its relationship with the historical period.

a. In the rising of text types, the effects of oral and written culture, social changes and interactions, and technology are emphasized.

b. Traditional theater (Karagöz, ortaoyunu, encomiastic, theatrical village play) and theatrical genres (tragedy, comedy, drama) and the scenario are mentioned. (p. 23)

The curriculum also includes the following explanations:

"A.3. 13. List the other important authors and works of the genre and period / movement.

a. Other prominent writers and works are mentioned.

b. In traditional theater, stereotyped famous plays (Example: Kanlı Nigâr) and famous encomiastic, kavuklu (a character in the ortaoyunu), pişekâr (a character in the ortaoyunu) and Karagözcü (Kel Hasan, Abdürrezzak, İsmail Dümbüllü, etc.) are mentioned.

c. Other important writers and works of the genre and the period / movement will be studied at 10,11 and 12th grade levels (TDEÖP, 2019)

In the 10th grade, it is written in the 6th unit theater type verbal communication section: "Information about Encomiastic is given. Students perform a short encomiastic play based on a encomiastic and stand-up performance. Karagöz videos are watched from the Internet." (TDEÖP: 44).

In line with these acquisitions and explanations, Heredot Cevdet can also be used as an example in Turkish Language and Literature course. Thus, students can learn these types better and these uses can have a positive effect on the continuousness of tradition.

As a result of the investigations, the following suggestions were developed:

1. Updated examples of tradition in teaching Turkish Language and Literature can be given in the context of student and life.

2. Other electronic narratives can be examined and brought into the educational environment with the tradition of meddahlık (eulogy show in ottoman culture and entertainment life).

Keywords: Turkish Literature, Meddah, Herodot Cevdet, Media, Traditional, Theatre.

Öz: Medyanın kullanımının yaygınlaşmaya başlaması ile edebi türlerin kullanımı da farklılaşmıştır. Kitaplar elektronik olarak okunmaya başlanmıştır, mektubun yerini elektronik mektup almıştır. Bazı edebi türler de medya kullanımı ile güncelleştirilerek sunulmuştur. Edebi kitaplar dizilere aktarılırken günümüz dünyasındaki görüntülerle karşımıza çıkmaktadır. Bir edebi tür olan meddahlık da medya ile hayatımıza farklı türde girmeye başlamıştır. Bazen tiyatro bazen stand up şeklinde karşımıza çıkan meddahlık bazen de dizilerin içinde karşımıza çıkar. Ekmek Teknesi dizisi içindeki Heredot Cevdet bu örneklerden biridir. Bu çalışmada, meddahlık bağlamında Ekmek Teknesi dizisindeki Heredot Cevdet anlatıları ele alınmıştır. Ekmek Teknesi dizisi 2002- 2005 yılları arasında üç sezon, yüz altı bölüm olarak yayınlanmıştır. Heredot Cevdet karakteri, geleneksel hikâye anlatma geleneği olan meddahlığın elektronik kültür ortamında güncellenmiş bir yorumudur. Dizinin her bölümünde, Heredot Cevdet genellikle sona doğru halk hikâyesi, destan, otobiyografik hikâye, tarihi hikâye gibi türlerde dinleyici kitlesine bir hikâye anlatır. Bu çalışmada meddah kavramı etrafında Heredot Cevdet anlatıları ve Türk Edebiyatı eğitiminde bu anlatıların kullanılabilme durumu incelenmiştir. Araştırma nitel araştırma yöntemlerinden doküman analizi ile 
hazırlanmıştır. Yüz altı bölüm olan dizide bu araştırmanın içeriği ile uyumlu on iki bölüm tespit edilmiştir: Leyla ile Mecnun (4. bölüm), Köktürk Yazıtları (6. bölüm), Ferhat ile Şirin (19. bölüm), Evliya Çelebi (22. bölüm), Çanakkale Şehitleri’ne (25. bölüm), Yusuf ile Züleyha (28. bölüm), Bülbülün Aşk1 (31. bölüm), Kerem ile Aslı (48. bölüm), Mehmetoğlu Mehmet (53. bölüm), Kırklar Dağı ve Suzan Suzi (54. bölüm), Oğuz Kağan Destanı (79. bölüm), T1kandı Baba (104. bölüm). Tespit edilen bölümlerdeki anlatılar öncelikle meddahlık geleneği ile karşılaştırmalı olarak incelenmiştir. Daha sonra anlatıların Türk edebiyatı öğretiminde kullanım durumu değerlendirilmiştir.

Anahtar Kelimeler: Türk Edebiyat, Meddah, Heredot Cevdet, Medya, Geleneksel, Tiyatro.

\section{Giriş}

Meddahlık uzun y1llar Türk toplumunda etkili olmuştur. Halkı eğlendirirken bilgilendirmeyi de amaçlayan meddahlık, geleneksel hali ile 20. yüzyıla kadar devam etmiştir. Meddah "seyirlik halk oyunlarının ortak ögelerinden bir bölümünü hikâyecilik hünerlerine katan ve böylece hikâye anlatmasına tek aktörlü bir oyunun niteliklerini kazandırma çabasında olan sanatçıya" ve bu sanatçının icra ettiği oyunun adına verilen addır (Kaya, 2010, s. 509). Meddah adlı halk hikâyecilerine Araplar kussas, Acemler kıssa-hân demiştir (Köprülü, 2012, s. 318). Arapça medh kökünden türeyen sözcük metheden anlamına gelir (Devellioğlu, 2004).

Nutku(2006, s. 44-45) Jacob'a göre meddahın, mesleği hikâye anlatmak olan bir konuşma sanatçısı olduğunu aktarır. Aynı zamanda anlatımını mimikle destekleyen bir oyuncudur. Walsh'e göre meddah çeşitli tipleri karikatürleştirirken hem hareketle hem konuşarak bu işi yapar .

Meddahlardan önce de Türk kültüründe hikâye anlatma geleneği vardır. Türk kültüründe hikâye anlatma geleneği şamanlarla başlamış, ozan, âşık ve meddahlarla devam etmiştir (Boratav, 2002, s. 85).

Meddahların anlatımları halk tarafından kolaylıkla anlaşılır. Seçtikleri konular hayatın içindendir. Meddahlar konularını hikâye kitaplarından, masallardan ve günlük hayattan alırlar, kahramanlarını günlük hayattan seçerler (Kaya, 2010, s. 509). Seçtikleri hikâyeleri ses tonuyla, jest ve mimiklerle zenginleştirirler. Taklit, benzetme ve abartma unsurlarına çoğu kez başvurmuşlardır. Bir anlatıda pek çok kişiyi taklit etmişlerdir.

Boratav(2002, s. 85) Jakob'a göre Türk halk hikâyeleri ile meddah hikâyelerinin farkının halk hikâyelerinin idealizmine karşıllk meddah hikâyelerinin realizmi olduğunu belirtir. Halk hikâyeciliğinde meddahlık, kahramanlık konularından realist konulara doğru bir gelişme göstermiştir. "Ülkücü ve romantik bir yapısı olan, doğaüstü kuvvetlerle olağanüstü olaylara geniş ölçüde yer veren halk hikâyeleri ile kıssahan hikâyelerine karşılık meddah hikâyeleri gerçekçi bir nitelik gösterir" (Kudret, 1995, s. 286). Meddah metinlerinde dev, peri gibi tabiatüstü varlıklara, insanüstü güçleri olan kişilere rastlanmaz (Kaya, 2010, s. 509).

Konuya hâkim olmaları, konu dışına bile çıkarken ana konuyla irtibatı koparmamaları ve dikkati canlı tutmaları kendilerine mahsus özelliklerdir. Sıradan gibi görünen konuları etkileyici hale getirirler. "Meddahların yan yana gelmesine münasebet olmayan şeyleri zahiren makul ve münasip bir tarzda yan yana getirerek halkı şaşırtmak ve bu suretle umumi alakayı arttırmak gibi müracaat ettikleri birçok usulleri, vasıtaları vardır." (Gerçek, 2006, s. 19).

Anadolu meddahlığının ne zaman başladığı kesin olarak bilinmemektedir. Saraylarda hükümdarları eğlendirmekle görevli kişilerin kıssahanlık ve meddahlık ettiği düşünülebilir. $\mathrm{Bu}$ kişilerin varlığı ise XIV. yüzyılda I. Bayazıd zamanından itibaren biliniyor. XVI. yüzyılda Türkiye'ye kahve geldikten sonra kahvehaneler açılmış, meddahlık yayılmış ve XVII. yüzyılda yaygınlaşmıştır. XX. yüzyılda yerini tiyatro ve sinemaya bırakmıştır (Kudret, 1995, s. 287-289). XVII-XIX. yüzyıl arası meddahların en güçlü olduğu dönemdir (Kaya, 2010, s. 511). 
XV. yüzyıldan itibaren meddah; kahramanların maceralarını anlatan, onların medihlerini yapan sanatkâr anlamında kullanılmaya başlanmıştır. XVIII. yüzyıldan itibaren meddahlar hikâyelerine mahalli unsurları daha fazla dâhil etmişlerdir (Boratav, 2002, s. 85).

Boratav (2002, s. 87) Jacob' a göre dünyanın birçok yerinde meddahlığın olduğunu belirtir. Eskimolarda, Çin'de, Japonya'daki taklitli halk hikâyeciliği, Hindistan'da Bhâna'lar Türk meddahlık sanatıyla karşılaştırılabilir(.)

XX. yüzyıla kadar devam eden meddahlık günümüzde değişmiştir. Bazen tiyatroda bazen stand up şeklinde bazen de dizilerde karşımıza çıkmaktadır.

Ancak stand up şeklini meddahlık olarak görmeyenler de var:

"Stand- up komedi, bir komedyenin sahneye çıkıp onu izlemeye gelenlerle doğrudan konuştuğu, genellikle toplumsal kişi ve olayları önceleyerek komik bir tarzda ortaya koyduğu gösteridir. Ferhan Şensoy stand- up komedi yapanlara "pop- komik" demiş, ortaya koyduğu gösterilerin tiyatro olarak kabul görmesi gerektiğini vurgulamıştır" (Korkmaz, 2019, s. 18).

20. yüzyıldan itibaren kahvehanelerde görülen geleneksel meddahlık bitmiş, gelenek ya tiyatroda ya da medyada görülmeye başlamıştır.

Kavuk, Beyoğlu'ndaki Ses Tiyatrosu'nda düzenlenen törenle Ferhan Şensoy'dan oyuncu Rasim Öztekin'e devredilmiştir. Öztekin, Hasan Efendi'den günümüze gelen ve 27 yıldır Şensoy'da olan kavuğun beşinci sahibi olmuştur. İsmail Hakkı Dümbüllü, ustası Kel Hasan'dan devraldığı kavuğu 1968'de oyuncu Münir Özkul'a, Münir Özkul da 1989'da Ortaoyuncular Tiyatro Topluluğu'nun kurucusu Ferhan Şensoy'a, Ferhan Şensoy ünlü kavuğu 27 yıl sonra oyuncu Rasim Öztekin'e devretmiştir (Hürriyet, 13.05.2016).

Ferhan Şensoy'u meddah olarak görmeyen araştırmacılar da vardır:

"Türkiye'de son geleneksel meddah diyebileceğim Erol Günaydın, söz cambazı olarak adlandırdığım Ferhan Şensoy ve meddahtan kalan sosyal boşluğu dolduran stand up'çı Cem Yılmaz gibi sanatçılarla görüşme ve söyleşiler yapıp, Polonyalı hikâye anlatma sanatı meraklılarına, Doğu kaynaklı meddahlığı, bir sanat dalı olarak tanıtmaya çalışmıştım"(Kaim, 2010, s. 112).

Çağdaş Türk tiyatrosunda, meddah sanatının bu özelliğine atıfta bulunarak, sözün yaratıcılığından ustaca yararlanan, "söz cambazı" sıfatını kullanabileceğimiz Ferhan Şensoy, tam anlamıyla meddah sayılmazsa da meddahlıkta var olan hicvin çarpık aynasında gerçek dünyayı göstermeye çalışan yazar görevini sürdürür. Ancak geleneksel meddah sanatçısıyla kıyaslandığında sözlü metnin bizzat yaratıcısı olarak kesinlikle daha aktif bir rol oynar" (Kaim, 2006, s. 274). değildir.

Günümüzde simge olarak elden ele geçen Kel Hasan'ın kavuğu aslında gerçek kavuk

“Gerçek kavuk Kel Hasan’dan Dümbüllü’ye verilmiştir. Dümbüllü de sanatın devamı için simgesel olarak Münir Özkul'a bir takke giydirmiştir ancak o takke gerçek kavuk değildir. Dümbüllü ustasından kalan kavuğun, fesin ve birtakım elbiselerin ölümünden sonra mezarına konulmasını vasiyet etmiş ancak din adamlarına sorulup onay alınamadığı için bu eşyalar damadı Mete Çingay’a teslim edilmiş ve onda kalmıştır" (Ataman (1974)dan akt. Durmaz, 2019, s. 25).

Tiyatrodaki bu meddahlık görünümü bazen de medyada karşımıza çıkmaktadır. Özellikle televizyonda sözlü gelenek yeniden inşa edilmiştir (Bars, 2019, s. 3). Geleneğin temel yapı taşları devam etmekle birlikte güncelleştirmeler de görülebilmektedir. Medyada karşımıza çıkan bu anlatılar Ong (2003)'un ileri sürdügü ikincil sözlü kültür ortamı ürünü olarak değerlendirilebilir. 2002-2005 yılları arasında üç sezon toplam yüz altı bölüm olarak yayınlanan Ekmek Teknesi 
dizisinde yer alan Heredot Cevdet karakteri, geleneksel hikâye anlatma geleneği olan meddahlı̆̆ın elektronik kültür ortamında güncellenmiş bir yorumudur. Dizinin her bölümünde Heredot Cevdet, dinleyici kitlesine bir hikâye anlatır. Halk hikâyeleri, destanlar, otobiyografik hikâyeler, tarihi hikâyeler ele alınan anlatı türlerindendir.

Bu çalışmada Heredot Cevdet karakteri ile meddahlık geleneği değerlendirilecek ve Türk Edebiyatı öğretiminde bu anlatıların nasıl kullanılabileceği tespit edilecektir. Türk edebiyat1 öğretiminde kullanılabilecek olan sadece on iki hikâye tespit edilmiştir: Leyla ile Mecnun (4. bölüm), Köktürk Yazıtları (6. bölüm), Ferhat ile Şirin (19. bölüm), Evliya Çelebi (22. bölüm), Çanakkale Şehitleri'ne (25. bölüm), Yusuf ile Züleyha (28. bölüm), Bülbülün Aşkı (31. bölüm), Kerem ile Aslı (48. bölüm), Mehmetoğlu Mehmet (53. bölüm), Kırklar Dağı ve Suzan Suzi (54. bölüm), Oğuz Kağan Destanı (79. bölüm), Tıkandı Baba (104. bölüm). Diğer anlatılar Türk edebiyatı kapsamında değildir, bu nedenle çalışmaya dâhil edilmemiştir.

\section{Yöntem}

Araştırmada doküman analizi yapılmış, veriler içerik analizi ile incelenmiştir.

\section{Araştırmanın Modeli}

Nitel modelde bir araştırma olan bu çalışmada durum deseni kullanılmıştır. Durum çalışması bir ya da daha fazla durumu derinlemesine betimlemek ve araştırma soru ve konularına dikkat çekmek amacıyla yapılır (Yıldırım ve Şimşek, 2013).

\section{Verilerin Analizi}

Verilerin analizi sürecinde, Ekmek Teknesi dizisinin yüz altı bölümü seyredilmiş ve içerisinde Türk edebiyatı öğretim programı da göz önünde bulundurularak içerikle alakalı on iki bölüm çalışmaya dâhil edilmiştir. Seçilen bölümler araştırmacılar tarafından tekrar izlenmiş ve dikte edilmiştir.

\section{Evren ve Örneklem}

Yüz altı bölüm olan dizide bu araştırmanın içeriği ile uyumlu on iki bölüm tespit edilmiştir: Leyla ile Mecnun (4. bölüm), Köktürk Yazıtları (6. bölüm), Ferhat ile Şirin (19. bölüm), Evliya Çelebi (22. bölüm), Çanakkale Şehitleri’ne (25. bölüm), Yusuf ile Züleyha (28. bölüm), Bülbülün Aşk1 (31. bölüm), Kerem ile Aslı (48. bölüm), Mehmetoğlu Mehmet (53. bölüm), Kırklar Dağı ve Suzan Suzi (54. bölüm), Oğuz Kağan Destan1, 79. Bölüm (79. bölüm), Tıkandı Baba (104. bölüm).

\section{Bulgular}

\section{Şahıs Kadrosu, Mekân, Zaman}

Dizideki Heredot Cevdet anlatısındaki belirgin şahıs kadrosu şu şekildedir: Heredot Cevdet, Ölü, Kıl, Veli Efendi, Nusrettin Baba. Heredot Cevdet anlatıların icracısıdır ve herkes tarafından bilgeliği ile tanınır, kendisine saygı duyulur: "Maşallah bizim tarih öğretmenimiz. Kendisinin bilmediği bir şey yok" (4. bölüm). Tarihçi Heredot'tan adını almıştır, tarihi seven ve tarihteki olayları anlatan kişi olması nedeniyle dizideki Heredot Cevdet ile tarihçi Heredot birbirine benzemektedir. Heredot Cevdet tarihi olayları güncelleyerek anlatmaktadır. Aynı zamanda "Cevdet" adı Ahmet Cevdet Paşa'ya bir göndermedir.

Oklay(2014, s.248)ın Chambers’ten aktardığına göre Ahmet Cevdet Paşa, Türk-İslâm kültürü ile Batı dünyası arasında sentez oluşturmaya çalışmışır. Anlatılara bakıldığında da Türk edebiyatına ait ürünlerin Batı edebiyatındaki örneklerle karşılaştırıldığı görülür. Anlatılara heyecan veren, heyecanın yükseldiği anlarda "Allah!" diye bağırarak dikkatleri toplayan karakter Ölü’dür. Anlatılarda Ölü heyecanı temsil ederken, çoğu anlatının sonunda "Aga, kafama bir şey takıldı!" diye soran Kıl da aklı temsil eder. Bazı yerlerde Kıl, sorularına cevap alabilmek için topluluğu, topluluk tarafından üst akıl olarak tanınan Nusrettin Baba'nın mekânına, Tekne(ekmek teknesi- 
fırın)'ye sürükler. Anlatılarda dinleyici kitlesini mahalleli oluşturmaktadır. Anlatıların sadece anlatıldığı kitle tarafından değil dışarıdaki insanlar tarafından da ilgi gördüğünü göstermek için Veli Efendi karakteri ile karşılaşırız. Veli Efendi, anlatıların sessiz takipçisidir. Nusrettin Baba cevap verilemeyen konuların danışıldı̆̆ı, konunun ehli olan, bilgi sahibi, bilge kişiliktir. Nusrettin Baba Heredot Cevdet'in de her zaman saygı duyduğu ve fikir aldığı bir kişidir, 20. yüzyılın Dede Korkut'udur. Burada da ateşin, acıların insanları olgunlaştırılmasına gönderme vardır. Ekmek teknesi fırındır ve fırında çalışan kişi ateşle iç içedir. Ateş maddeyi, acı insanı olgunlaştırır. Nusrettin Baba'nın bilgeliği ile ateşin ekmeği olgunlaştırması bütünleştirilmiştir.

Anlatılardaki mekân ve zaman geleneksel meddahlığa benzemektedir. Heredot Cevdet anlatılarının incelenen bölümlerinde icra mekânı 4. bölüm hariç kahvehanedir ve insanlar Heredot Cevdet'in etrafında yarım ay ş̧eklinde otururlar. $\mathrm{Bu}$ durum klasik meddah geleneğine de benzemektedir. "Meddah gösterisi için bilinen ve en yaygın olarak kullanılan yer kahvehane veya kıraathanelerdir" (Sekmen,2008: 48). Zaman ise herkesin dinlenmeye çekildiği akşam vaktidir.

\section{Aksesuarlar}

Meddahların aksesuarları genellikle sandalye, baston veya sopa, mendil veya makramedir. Meddahlar, kahvehaneye girdiklerinde bazen sandalyeye otururlar. Heredot Cevdet de kahvehaneye girince sandalyeye oturmaktadır. Sopayı, yere üç defa vurulduğunda olduğu gibi, dikkati toplamak için; mendili de taklit yapmak için kullanırlar. Heredot Cevdet sandalye dışındakileri kullanmamaktadır. Ancak dikkati toplamak için çay bardağını üç defa masaya vurmaktadır. Çay bardağı anlatıda sopa görevini görmektedir.

\section{Dil ve üslup}

Klasik bir meddahın hikâye anlatırken kullandığı tekerlemeler, söz sanatları, taklitler ve benzetmeler Heredot Cevdet'te de görülür. Çalışmaya dâhil edilen, incelenen metinlerde bu unsurların hepsi görülmemektedir. Anlatıda bunlardan farklı olarak bilmece yer almaktadır. Yusuf ile Züleyha anlatısının başlangıcında bir Sivas bilmecesine yer verilir:

"Eeey hurtlar huuurtlar

Yusuf'u yiyen kurtlar

Ayağından su içer

Tepesinden yumurtlar!"

İkileme ve tekrarlara yer verilmiştir. Anlatılarda görülen kelime tekrarları; icrada inandırıcılık, etkileyicilik, heyecan gibi işlevlere sahiptir.

“Bülbül, gülün bu halini görebilmek için var gücüyle ötmüüüş ötmüüüüş ötmüüüüş.

... Gül ise sevdiğinin en güzel halini görebilmesi ümidiyle bir ömür boyu açmı1ş açm1111ş solmuş.

...Bülbül güle öyle sevdalanmış öyle sevdalanmış ki onun her halini görmek istemiş. Yaprağın da beniiiim dikenin de beniiim; ezan da benim cefan da benim olsun demiş. Gül de sevdalısının sesine öyle meftun olmuş ki ona en güzel kokularından hediye edebilmek için bir solmuuuş bir açmış bir solmuuuş bir açmış ve ona en güzel halini göstermek istemiş." (Bülbülün Hikâyesi)

“...sonra Kapıkule Sınır Kapısı'ndan giriş yapmış ve kutsal memleket toprağına kapanıp öpmüş öpmüüüş öpmüşşs” (Evliya Çelebi)

\footnotetext{
“...Ardındaki yüzbinlerce ton su, Ferhat'ı yuttu, Şirin'i yuttu, Şirin'in bedbaht ablasını yuttu, bütün şehri yuttu. Ama bu aşkı yutamadı.” (Ferhat ile Şirin)

“...Fakat bu yerden bitme Çinlilerin fitnesiyle fücürüyle koskoca imparatorluk tespih taneleri gibi dağıldı.” (Köktürk Yazıtları)
} 
Kerem ile Aslı hikâyesinde tekrarlar, anlatının gücünü artırıcı bir işleve sahiptir:

“...Kerem, Aslı’nın gelinliğinin düğmelerini çözdükçe düğmeler kapanmış. Meğer kızın keşiş babası büyü yapmış. Oğlan, düğmeleri çözmüş, düğmeler kapanmış. Oğlan, düğmeleri çözmüş, düğmeler kapanmış. Sabahlar olmuş. Şaşkın Kerem, 'Bu işin aslı nedir Sultanım?' diye sormuş. Aslı, kerem edin çözün efendim demiş. Kerem çözememiş, çözememiş yanmış, kavrulmuş, ateş olmuş, kor olmuş, kül olmuş. Aslı, sevdiğinin küllerine kapanmış hüngür hüngür ağlarken o da saçlarından tutuşmuş alev olmuş, ateş olmuş, kor olmuş, kül olmuş, kul olmuş. Aslı, Kerem olmuuuş; Kerem, Aslı olmuuuş. Bir rüzgar esmiş, bu aşk, bu sevda bütüüüün dünyaya savrulmuş. İnsanlar bu kokuyu koklaya koklaya sevmeyi öğrenmişler.”

Leyla ile Mecnun hikâyesinde de Kerem ile Aslı hikâyesinde olduğu gibi anlatının duygu yönü kelime tekrarları ile sağlanmıştır:

“...Mecnun içinde bulunduğu bu olağanüstü aşk üzerine her gördüğü nesneyi, ağaçları, taşları, toprakları, kedileri ve uyuz köpekleri Leylaaaa Leylaaaaa Leylaaaaa diye sarılıp öpmektedir. ... ve bir gün bir palmiye ağacının dibinde hem de kurumuş bir palmiye ağacının dibinde Leylaaa Leylaaaa Leylaaa diyerek eşhedü enla’yı çekip ruhunu teslim ediyor."

Mehmetoğlu Mehmet anlatısında anlatımın etkisini artırmak amacıyla kelime tekrarları oldukça önemli bir yer tutar:

“Ama, gelgelelim Mehmetçik'in başına yağmur gibi kurşun değil kar yağıyor! Milyonlarca kar tanesi, o nar tanesi, nur tanesi, anneciğinin bir tanesi Mehmetçik'in başına afet olmuş yağıyor!

Mehmet aç, Mehmet çıplak, üzerlerinde incecik yazlık elbise, ayaklarında yırtık pırtık çarıklarla yürüyorlar o vuuu vuuu esen tipinin, ayazın altında!”

"Kar, mermi olmuş, havan olmuş, alev makinası olmuş, Mehmetçik'i yakıyor! Gökyüzünden düşen her bir kar tanesi, gözyaşlarını tutamıyor, bu defa da o gözyaşları donup Mehmetçik'in tertemiz alnına düşüyor! Mehmedim, en önde bata çıka yürüyor! Bata çıka yürüyor, bata çıka yürüyor! Bakıyor uzaklara: beyaaaz, beyaaz, beyaaaaz.... Mehmet'in ayakları duruyor! Mehmedimin kalbi yürüyor ama ayakları duruyor! İște o anda çekiyor mavzerini, bağırıyor: Yürü, kopasıca ayaklarım! Yürü! İşte, bu manzarayı gören çam ağaçları, o dökülmesi imkansız yapraklarını üzüntüden döküyor. Ulu çınarlar hüngür hüngür ağlıyor! Mehmet'in ayağı kardan çıkamıyor! Ayağına geymiş kara yemeniii, sallanma Mehmedim öldürdün beni! Mehmet! O bembeyaz karların içerisine düşüyor, yer beyaaaz, gök beyaaaaz, sağ beyaaaz, sol beyaaaz, Mehmet'im kalkıyor ama karrrr o yazlık lime lime olmuş asker kaputunu delip de geçiyor! Karrr, Mehmet'in boyuna geliyor! Mehmet'i içine alıyor! Mehmet, yok oluyor! Sonra bir Mehmet daha birr Mehmet daha birr Mehmet daha! Düşen her kar tanesinde bir Mehmet düşüyor! Doksan bin kar tanesi! Doksan bin nur tanesi! Su oluyor, toprak oluyor, yok oluyor, var oluyor!"

Tıkandı Baba hikâyesinde de anlatının gücünü artırma işleviyle ikilemelerden yararlanıldığı görülür:

"Hepsinin birer çeşmesi vardı ve hepsinin çeşmesinden de şırıl şırıl sular akıyordu. Benim çeşme de akıyodu ama az akıyodu. İçimden keşke benimki de onlarınki gibi gürül gürül aksa diye geçirdim..."

“...Bir bakmış: bir koca altın! Diğer dilim, diğer dilim, diğer dilim derken her dilimin altında bir altın!...”

Burada ikileme, anlatıya heyecan ve hız katmıştır. 
Anlatılarda benzetme de görülmektedir. Bülbül ile gülün aşkı, Leyla ile Mecnun'un aşkına benzetilir: "Asırlardır dillenen, dilden dile söylenen gahi Leylaaa gahi Mecnuuun öyle ya her âşıkın bir ahı var!" (Bülbülün Hikâyesi)

Anlatılarda mübalağalardan da yararlanılır. Bülbülün Hikâyesi anlatısında, anlatının kahramanları olan gül ile bülbül mübalağa sanatı ile verilir: "Bir küçücük güllen minicik bir bülbülün devyarasa aşkıdır bu!" (Bülbülün Hikâyesi). ile aktarilır:

Evliya Çelebi anlatısında, Evliya Çelebi’nin gezdiği yerler ve gördükleri mübalağa sanatı

“Devlet-i Ali-i Osmaniye'de gezmediği bir tek karış toprak kalmamış kardeşim!

Neler görmemiş, neler! İp üzerinde kurban kesip derisini şişiren tel cambazları, damdan dama atlarken soğuktan havada donan kediler, rakkaseler, çengiler, zenneler, zerdeler, aşureler, beyler, paşalar, hanlar, hamamlar, eşkiyalar. Fil doğuran kadınlar bile görmüş. Anlayacağınız zamanının Heredot'uymuş!” (Evliya Çelebi).

Ferhat ile Şirin hikâyesinde, âşıkların kavuşması hadisesi de mübalağa ile anlatılmıştır:

"Dağ dağa kavuşmaz ama insan insana kavuşur derler. Ama bu kavuşmak öyle hepinizin bildiği gibi kolay olmaz. Öyle aşklar vardır kii asırlar geçse unutulmaz. Çekilen acılara dağ olsa dayanmaz! Ortasından çat diye yarılıp gözyaşlarını bir Niagara misali püskürtür, âş̧ıların önünde kum tanesi gibi dağılır!” (Ferhat ile Şirin) anlatılmıştır:

Aşkın vuku bulma hadisesi de Ferhat ile Şirin hikâyesinde mübalağalı bir şekilde

"Sorarım size, böyle şahane bir manitayla böyle yağız bir delikanlı arasında aşk yaşanmıcak da kimin arasında yaşanıcak? Her aşkın bir başlangıcı vardır. Bir anda göz göze gelirsin, bir şimşek çakar, bir gök gürültüsü patlar, bütün tabiat, ortalık birbirine girer, mahlukat ciyak ciyak ötüşür de bundan o iki kişiden başka hiç kimsenin haberi olmaz. İşte aşk budur."

Ferhat ile Şirin hikâyesinde anlatının inandırıcılığını artırmak amacıyla Heredot Cevdet, çayını havaya kaldırır ve biraz döker. Bu görsellik kan ile özdeşleştirilir. "Yalanım varsa kanım böyle aksın" diyerek anlatıya inandırıcılık katılmaya çalışılır:

“...Şirin'in ablası, aynı zamanda ülkenin sultanı ve hükümdarı Mehmene Banu da pencereden gizli gizli bakarken Ferhat'1 görmüş ve ona âş̧ı olmuştur. Fakat pozisyonu ve kariyeri gereği protokolü çiğiniyip halka rezil olmamak için odasında gizli gizli ağlamış ve bu aşkı içine gömmüştür. Yalanım varsa kanım nah böyle aksın!"

Aynı durumu Köktürk Yazıtları anlatısının icrasında da görmekteyiz: "Delikanlının biri çıktı: İlteriş Kağan! Yalanım varsa kanım na böyle aksın" dedikten sonra Heredot Cevdet, masasına gelen çayı havaya kaldırır ve biraz döker. Anlatıyı görselleştirme noktasında bu önemli bir noktadır. Böyle su gibi aksın, böyle çok aksın...

Mübalağa sanatı, anlatının inandırıcılığını artırmak amacıyla aynı anlatının farklı bölümlerinde de kullanılmıştır:

“...Aldı eline murç ile çekici devasa kayaların üzerine draan draaan diye vura vura mektubunu yazmağa başladı... İşste tek tek, kalem kalem avuçları patlayıncaya kadar devasa kayaların üzerine bunları yazdı." (Köktürk Yazıtları). görülür:

Kerem ile Aslı hikâyesinde, aşkın büyüklügüne dair inandırıcılıkta da mübalağa sanatı

"Kardeşlerim! Bugün size aşkın, sevdanın ciğer (elini kalbine vurur) gibi kavrulup yanmanın aslını faslını, Kerem ile Aslı'nın yürekler dağlayan, basiretler bağlayan aşkını anlatıcam! Bu öyle bir aşk, öyle bir sevda, öyle bir ateş-i suzan ki insanı cayır cayır çıra 
gibi yakar da Çemberlitaş Hamamı'nın külhanı bu aşkın karşısında Kuzey Kutup

Dairesi gibi kalır! “(Kerem İle Aslı)

Sarıkamış Faciası'nın büyüklüğünü vurgularken mübalağa sanatından faydalanılmıştır:

"Sarıkamış! Tarihimizin kalplerimizde açtığı en derin yara! Sarıkamış! Türk Ordusu, Rusları Kars'tan, Ardahan'dan, Sarıkamış'tan atmak için üç bir koldan taarruz ediyor!'(Mehmetoğlu Mehmet).

Züleyha'nın Yusuf'a olan aşkı da mübalağa sanatı ile aktarılmıştır:

“O Züleyha ki Yusuf’a bakmalara doyamamış. Öyle âşı olmuş öyle âşık olmuş ki yedi düvelin diline sakız olmuş.”(Yusuf ile Züleyha).

Anlatılarda betimleme ve benzetmelerin iç içe geçtiği görülür. Bülbülün Hikâyesi anlatısında bülbülün gülü betimleyişi:

"Kaşları yayı1ım, çehresi ayı11m,

Benlerin çoktur, akranın yoktur,

Bir yüzü mahım, zülfü siyahım,

Bakıp durmalı, cana sarmalı, hemen almalı!"

Gülün bülbülü betimleyişi:

"Ah benim efendim, servi bülendim

İzzette yekta, saadette bihemta

Muhabbette lanazir, güzellikte bikusur

Candan azizim, şekerden lezizim

Efendim, canım, sultanım

Makbulünüz olmaktır niyazım!"

Ferhat ile Şirin hikâyesinde de Ferhat ile Şirin'in betimlenmesinde mübalağa ve benzetmenin iç içe geçtiği görülür:

Ferhat: "Ferhat ise, uzun boylu, geniş omuzlu, gözleri sürmeli, alnı kahküllü, na böyle kafam gibi pazuları olan yakışıklı bir nakkaşmış. Elindeki balyozunu bir salladı mı dağı taşı un ufak ediyor Florya Güneş Plajı'na kum yapıyormuş karrrdeşim!"

Şirin:

“Kara kaşlı, kara gözlü, açık sözlü, dilber dudaklı, buğday tenli, 1.76 boylarında, 46 kilo aslında biraz da etine dolgun, bugün yaşasa en kral hostese taş çıkartacak bir donanıma sahip, ay parçası gibi, güneş kenarı gibi, Büyükayı takım yıldızını hasedinden çat diye çatlatıp Küçükayı takım yıldızına çevirecek, en güzel, yüzüne bakmağa bile doyamıycağın cillop gibi bir manitaymış!"

Kerem ile Aslı hikâyesinde Kerem ve Aslı, mübalağa sanatı ile betimlenir:

“Kardeşlerim! Kerem, Isfahan Şahı'nın oğludur. 16. yüzyılda yaşamış âş̧ılar arasında aşka en istidatlı, en kabiliyetli olanıdır. Öyle ki daha çocuk denecek yaşlarda çiçeğe, böceğe, dağa, taşa âşık olmuş; güfteler, şiirler, şarkılar düzmüş.

Küçük yaşta aldım sazı elime

Dertli dertli vurdum sazın teline 
Diyen, günümüzde yaşasa komple manken camiasının imaj makerlarını hiçe sayıp kapısında yatıp kalkıcağı, uğruna ücretsiz mayo defileleri düzenliyeceği kara kaşlı, kara gözlü, dalyan gibi bir delikanlıymış! (Çayından bir yudum alır.)

Assslı11ı! Aman Yarabbim! Zamanının en güzeli, güzellikten fincancı katırlarını ürküten, yaşıtı genç kızları aynalara küstürüp kıl ettiren, ulan bu kadınsa biz hangi yaratık sınıfına giriyoruz dedirten, sürüler halinde estetik uzmanlarına koşturan - ki ilk estetik o dönemde yapılmıştır. Güzellik müsabakalarının FİFA ve benzeri kurumlar tarafından süresiz yurtdışına alınmasına sebep olan, cillop ötesi, doğal sarışın, tabii afet, ay tutulması, güneş kasılması, El Nino kasırgası gibi bir Allah vergisiymiş karrrdeşim!” betimlenir:

Kırklar Dağı ve Suzan Suzi anlatısında Suzan ve âşık olduğu genç mübalağa sanatı ile

"Suzan Suzi yüzüne baktığında bütün sağlam gözleri 2 derece miyop, 22 derece de astigmat yapan, yaldır yaldır yanan, haldır haldır yakan, kara üzüm habbesi gibi bir genç kız olmuş. Giderken gelirken, akaradır makaradır derken yakışıklı ibaresinin yakışıksız kalacağı, limitsiz yakışıklılık sembolü Müslüman komşularının oğlu Adil’e âşık olmuş."

Leyla ile Mecnun hikâyesinde de Leyla ile Mecnun betimlenirken mübalağa sanatından faydalaniliyor:

"Mecnun, nüfus kâğıtlarındaki gerçek adı: Kays. Varlıklı bir ailenin Paşa çocuğu. Bir eli yağda, öbür eli balda. Yediği önünde yemediği arkasında. Yakışıklı, civanmerd, dalyan gibi bi delikanlı! Doğan aya doğdum diyor, böyle bir delikanlı! Diğer köşede ise, Leyla, bir özge can! Bir afet-i cihan! Öylesine süper bi manita ki değme mankenlere taş çıkarıyor. Amman sabahlar olmasın!"

Sarıkamış Şehitleri'nin anlatıldığı Mehmetoğlu Mehmet anlatısında, Mehmet'in betimlenmesi de yine mübalağa sanatı ile iç içedir:

"Yıl 1914. Gencecik, zeytin dalı gibi ince, ceviz dalı gibi endamlı, gül dalı gibi bülbül sevdalı, yüzüne baktığında komple bütün bahar çiçeklerini açtıran, ırmakları coşturup coşturup çağlatan, basiretler bağlatan bir delikanlı. Adı Mehmet. Mehmetoğlu Mehmet! Okumuş, yazmış, öğretmen olmuş, kendini kendi gibi olan yavrucakların okumasına adamış, kar kış demeden boydan boya, kara tahtanın karasına, tebeşirin beyazına bulanıp yavrucaklar yetişsinler, vatanlarına milletlerine faydalı insanlar olsunlar aşkıyla yanıp tutuşan, halis muhlis bir Türk delikanlısı!"

Mehmet'in âşık olduğu Gülendam da yine mübalağa sanatı ile iç içe aktarılır:

“Alfabenin 29 harfinin yerini değiştirten, sesli harflerin sesini kıstırtan, sessiz harflere ulan biz böyle güzellik görmedik! Diye bar bar çığlıklar attıran, edatları, zamirleri, bağlaçları, komple dilbilgisinden istifa ettiren, en güzel, yüzüne bakmağa doyamıycağın cillop gibi bir hanım kız."

Oğuz Kağan Destanı'nın anlatıldığı bölümde de benzetmelerin mübalağa sanatı ile iç içe olduğu görülür:

Oğuz Kağan, "Kara kaşlı, kara saçlı, ela gözlü ve kırmızı ağızlıydı. Perilerden bile daha güzeldi." şeklinde betimlenirken Oğuz Kağan'ın ilk eşi şu şekilde betimlenmiştir:

“Güneş’ten, Ay’dan, bütün takımyıldızlardan daha parlaktı. Aha, o 1şığın içerisinden doğan aya doğdum diyen, yüzünden alevler, 1şıklar saçan, dudağında bir beni, kutup yıldızı gibi bir kız zuhur etti." Şeklinde ikinci eşi ise "Oğuzhan dere kenarında avlanmaya çıkmışken bir ağacun kovuğunda akılları cayır cayır yırtan, gözleri yuvalarından pöttür pöttür pötleten güzellikte bir k1z gördü. Saçları omuzlarından Niagara Şelalesi gibi akıyordu. Gözleri, gözleri bulutsuz gökyüzünden daha maviydi. Dişleri, adeta birer inci tanesi. Dikkatinizi celbederim! Sıkma plastik diğil, gerçek inci!". 

verilmiştir:

Yusuf ile Züleyha adlı hikâyede yine kahramanların betimlemesi mübalağa sanatı ile iç içe

Yusuf:

"O zaman kadar kainata böyle güzel bir insan gelmedi. Öyle bi güzellik ki doğan aya doğdum diyor. Komple bütün takımyıldızları Büyükayı, Küçükayı, Samanyolu ve hatta Halley kuyruklu yıldızı bile esas duruşa geçip bu güzellik karşısında selam duruyorlar. Nasıl durmasınlar kardeşim, Yusuf bu! Güzellik oo, dürüstlük oo, cömertlik oo, yiğitlik oo, ay o, yıldız o, gece o, gündüz o. İnsan bakmalara kıyamıyor. Adeta bir güneş gibi gözleri kamaştırıyor."

Züleyha:

"O, güneş ama Züleyha da ay. Ay parçası gibi yüzüne bakmağa doyamıycağın, en güzel, cillop gibi, daldaki elma, sudaki nergis, havada uçuşan leylak kokusu, bülbülün dilindeki gül, gülün içindeki gonca, dağ yolundaki yonca Züleyha bu Züleyha! Dünya'da bir tek kişi yoktur ki Züleyha’yı görür görmez âşık olmasın. Malını mülkünü, şanını şöhretini terk etmesin!”

"Netice itibarıyla bir erkek olarak Yusuf, Züleyha'nın güzelliğini müşahede etse de adeta çelikten yapılmış sinirleriyle duygularını inkitaya uğratmayı başarmış."

"Yusuf'u iftirayla zindanlara attıran bu bedbaht kadın aşkından erimiş, eprimiş, gözünün feri sönmüş, beli bükülmüş, yüzüne bakmağa tırsıcağın en korkunç bir cazı karısına dönüşmüşs."

Türk destanlarında göçebe yaşamın da etkisiyle kısa cümle yapılarının tercih edildiği, hiçbir sözcügüün gereksiz yere kullanılmadığı görülmektedir. Heredot Cevdet'in Oğuz Kağan Destanı'nı anlattığı bölümde buna dikkat ettiğini görmekteyiz. Cümleler kısadır, süslü ve abartılı betimlemeler son derece azdır. Anlat1, klasik destan kurgusuna uygundur.

"Bir anda akabinde ve detayında çadırın kapısından içeri güneş gibi bir ışık girdi."

Yusuf ile Züleyha hikâyesinde de geçen zaman “... Derken akabinde ve detayında Mısır'1 her türlü kalkındıran açlıktan ve kıtlıktan kurtaran Yusuf memleketimde aç hiçkimse kaldı mı diye sokakları dolaşırken..." şeklinde ifade edilir.

\section{İcranın Hazırlık Așaması}

Heredot Cevdet, kahvehaneye "Selamun Aleyküm kahve milletinin insanları!" hitabiyla girer ve o akşam anlatacağı anlatıyla ilgili ipucunu icranın hazırlık aşamasında belirtir: "Ben de dağ gibi adam nereye kayboldu diyodum ya. Dağ dedim de size dağlanı delen Ferhat'ın hikâyesini anlattım mı?" (Ferhat ile Şirin).

"Ulan Taarruz Keçisi, lingir lingir ne dolaşıp duruyosun masaların arasında Evliya Çelebi gibi. Patlatsana çayları!

Tüm bardaklar dolsuuuun!

Patlatsana çayları dedim de size Evliya Çelebi’nin hikâyesini anlattım mı?

Anlatmadın Baba, anlatsana!

Yaklaşın bakiyim yamacıma, seyahat edin! Hadi! Seyahat edin, yaklaşın!” (Evliya Çelebi)

"Taş dedim de siz taşlara yazılan mektupların hadisesini biliyo musunuz?

Bilmiyoruz. Hadi anlatsana!

Bi çay ateşle de anlatayım Taarruz!

Emredersiniz! Tüm bardaklar dolsuuuun!" (Köktürk Yazıtları) 
Bazı anlatılar ise dinleyici kitlesinin isteğine göre anlatılır. Bu tarz anlatılar genellikle aşk hikâyeleridir ve âşı olan kişilerce anlatılması talep edilir:

"Selamun Aleyküm kahve milletinin insanları!

Aleyküm Selam!

Celal: Babacım be, hususi bi ricam olucak.

Heredot Cevdet: Söyle güzel kardeşim beniim.

Celal: Bi aşk hikâyesi anlatsanız da şöyle gözlerimizden on on döksek!

Heredot Cevdet: Senin kalbin temizmiş be! Hem de en kralını anlatcam! Kahve milletinin insanlar! Dikkatinizi celbederim! Şu dakikadan itibaren diğil çay içmek bardak karıştırmak dahi memnudur. Çünki şahıslar büyük, mevzu ağırdır. Kulaklarınızı dört açın! Hz. Yusuf ile Züleyha'nın o büyük aşkı geliyor" (Yusuf ile Züleyha)

Kimi anlatılarda Heredot Cevdet'in kahveye girişi ve dinleyici kitleyi selamlama kısmı gösterilmez. Heredot, çayına şekerini atar ve çayını karıştırarak ilgiyi üzerine toplar. İlginin üzerinde olduğunu anlayınca:

“Kardeşlerim, ben size Tıkandı Baba'nın hikâyesini anlatıım mı?

Anlatmadın Baba, anlat anlat!

E o zaman toplanın bakiyim yamacıma, toplanın, yaklaşın bulaşıklar! Safları sıklaştırın, doldurun, boşluk kalmasın! Aman dikkat, tıkanmasın yollar! “(Tıkandı Baba)

Dinleyici kitleden icranın gerçekleşme iznini aldıktan sonra hikâyesini anlatmaya başlar. Heredot Cevdet, çayını karıştırır ve dinleyicilerin dikkatini çekmeye çalışır: "Çıt çıkaranın kafasını koparırım, ona göre! (Mehmetoğlu Mehmet)

İcranın hazırlık aşaması; dinleyici kitlenin selamlanması, Heredot'un anlatacağı anlatıyla ilgili ipucu vermesi, dinleyici kitlenin anlatının anlatılması yönünde istekte bulunuşu, Heredot'un anlatıya başlamadan önce çay istemesi, çaycının “tüm bardaklar dolsuuuuun!” çağnısıyla icranın başlayışının duyurulması aşamalarından oluşmaktadır.

Geleneksel meddah anlatılarında meddahın sopasını yere üç kez vuruşuyla icranın başladığını belirten işaretinin Heredot Cevdet anlatılarında "tüm bardaklar dolsuuuuun!" cümlesiyle kimi zaman da Heredot Cevdet'in çayını karıştırarak ilgiyi üzerine çekmesiyle güncellendiğini söylemek mümkündür. Çay, icrada kimi zaman Heredot Cevdet'in bir yudum alarak dinlendiği öge olarak da karşımıza çıkar. Bu, geleneksel meddahın icra esnasında alnını bir an için elindeki mendiliyle silmesini karşılar. Çanakkale Şehitleri’ne bölümünde Heredot:

"Ulan Taarruz Keçisi, çaylar kalsın millete birer bardak su getir, önlerine de birer peçete koy. Her ne kadar Cengiz kardeşimiz ne şehittir ne gazi olduysa da ben sizlere bugün Çanakkale Şehitlerimiz'in hikâyesini Mehmet Akif Ersoy'un ağzından anlatıcam." der. Konu, ciddiyet ve saygı gerektirdiğinde anlatı boyunca çay içilmesi uygun görülmez. Bu nokta da çayın anlatılarda eğlence işleviyle yer aldığının işareti niteliğindedir. Taarruz:

“Tüm gözler kanla dolmadan tüm bardaklar suyla dolsun” der ve icranın anlatımına başlar.

\section{İcranın Anlatımı}

Zaman kavramı kapsamında; "derken akabinde ve detayında" söz grubu, masallarda geçen zamanı vurgulayan "az gittik uz gittik, dere tepe düz gittik./ kırk gün kırk gece/ yedi gün yedi gece gibi söz gruplarıyla benzer işlevde kullanılmıştır.

Zaman kavramı, Kırklar Dağı ve Suzan Suzi hikâyesinde: "Günler günleri kovalamış, yıllar yıllara nanik yapmış..." şeklinde yer almıştır (Kırklar Dağı ve Suzan Suzi). 
Anlatı sırasında öğüt verici sözler de kullanılmıştır:

"Kardeşlerim!

Sakın ola ki biri ottur biri kuştur diye küçümseme gafletine düşmeyesiniz. Sonra öyle bi bülbül olursunuz kii daha ötmesini bilmeden gülün goncasını açmasını bekleer durursunuz." (Bülbülün Hikâyesi)

Evliya Çelebi hikâyesinde, Evliya Çelebi’nin babasının sözleri:

"Yürü ileri gözüm kalma geri

Alay bozma, tarla basma

Dostlarının ayağına sarkma

Komadığın yere el uzatma

İki kişi konuşurken dinleme, -her ne kadar iki kişinin bildiği sır değilse de.

Davetsiz bir yere sakın varma

İyi huylu ol, inatçı ve sivri dilli olma

İhtiyarlara hürmet et

Bayramlarda Darülaceze'yi ziyaret et

Sirrın varsa sakın avradına deme

İyi adını kötüye takma

Dünyalık akçe için namerde muhtaç olma demiş ve Eşhedü enla’yı çekip ruhunu teslim etmiş." (Evliya Çelebi)

Heyecanı canlı tutmak ve dikkati toplamak için ses kimi yerlerde yükseltilmiştir. Heredot Cevdet'in "Kardeşlerim!" seslenişi, icranın başlangıcında kimi zaman da icranın ortasında dağılan dikkatin toplanması işleviyle kullanılmaktadır. Yükselen heyecanın zirve noktasını Ölü'nün “Allah!” diye bağırışı gösterir. Anlatı, bu bağırıştan sonra normal seviyeye iner:

“Allah kalbimize bu aşkı koyduktan sonra Şirin'imiz için iktiza ederse koskoca dağı da deleriz, diyip eline balyozunu aldı Yaradan'a sığındı ve Allah diyerek koskoca devyarasa dağa indiriverdi.” Ölü, burada "Allah!” diye bağırır. (Ferhat ile Şirin)

“....ve İlteriş Kağan'ın bu çağrısı üzerine bütün Türkler bir araya gelip toplandılar ve süper bir devlet kurdular Göktürkler. Bütün dünyaya hükmetmeye başladılar.” Ölü’nün “Allah!” diye bağırması ve anlatının heyecanının normal seviyeye dönmesi. (Köktürk Yazıtları)

Köktürk Yazıtları'nda:

"Ulusum! Budun! İşiding!

Üze Tengri basmasa

Asra yir telinmese

Türk ulusi özini törüni kim atadı!

Aman sabahlar olmasın!" sözleri de anlatıda heyecanın arttığı noktada dile getirilmiştir.

“... Münih’e gitmiş. Bira bahçelerinde, Çin hamamlarında, Fin hamamlarında, saunalarda en güzel yüzüne bakmağa doyamıycağın cillop gibi yumurta sarısı Alman Helga'ları görmüş. Amman sabahlar olmasın!" (Evliya Çelebi)

Ferhat ile Şirin hikâyesinde bu kalıp ifade, aşkı anlatma işleviyle karşımızdadır: 
"Ferhat, Şirin'in ablasının sarayında nakkaşlık yaparken bir gün Şirin'i saltanat paytonuyla geçerken görür. Bir anda göz göze gelirler ve aynen yukarıda anlattığım tabiat hadisesini bir anda yaşarlar. Amman sabahlar olmasın!"”

Oğuz Kağan Destanı'nda anlatının heyecanının yükseldiği ve artık destanın sonlarına yaklaşıldığ bölümde: "Oğuzhan, Eeeey küçük kardeşler! Bu üç gümüş ok sizlerin olsun, sakın kaybetmeyin. Ama okun da yaysız olamayacağını sakın unutmayın!" nasihatında bulunur ve burada Ölü, “Allah!” diye bağırır.

Fuat Köprülü'nün Güldeste-i Riyâz-1 İrfan'dan aktarımına göre 1616 yılında Bursa'da şair Haylî Ahmed Çelebi kahvede "Bedi ve Kasım" hikâyesini anlatırken topluluk kendini hikâyeye kaptırmıştır. Bir bölümü Bedi'yi bir bölümü Kasım'1 tutmaktadır. Haylî Çelebi de Kasım'1 tutmaktadır. Aynı anda kahvede Saçakçızade de başka bir hikâye anlatmaktadır. Haylî Çelebi Saçakçızade'yi kendisiyle alay ediyor diye biçaklayarak öldürmüştür (And, 2006, s.4). Heredot Cevdet'in anlatılarında da Ölü karakteri anlatılar sırasında kendisinden geçmektedir. Bu durum da anlatıların inandırıcılı̆̆ını göstermektedir.

Oğuz Kağan Destanı’nın anlatıldığı bölümde, “...Düştüler kurdun peşine, o gök tüylü gök yeleli kurdun peşinde nice zaferler kazandılar. Sayısız ülkeleri il yapıp sınırlarına dahil ettiler. (...)" Burada Heredot çay içerek kısa bir mola verir, dinleyici kitlesi de çay içer. Burada çay, dağılan dikkatin toplanması, kısa bir an soluklanma işleviyle karşımıza çıkar.

\section{Motifler}

Rüya: Evliya Çelebi hikâyesinde Evliya Çelebi'nin rüya görmesi buna örnektir. Tıkandı Baba hikâyesinde Tıkandı Baba, rüyasında herkesin bir çeşmesi olduğunu görür, kendi çeşmesinden daha az su aktığını görünce çeşmeye çomak sokar, bu şekilde uzun bir süre uğraşır ve bir melek görür “.... Ben yine açmak için uğraşırken bir melek göründü: T1kandı Baba, tıkandı, artık uğraşma dedi. İşte o gün bugün adım Tıkandı Baba'ya çıktı. Hangi işe el attıysam olmadı, biz de işte burada gördüğün gibi çaycılık yapıp geçinmeğe çalışıyoruz."

Âşıkların Kavuşamaması: “Derler ki yıllar sonra Ferhat'la Şirin'in mezarı yan yana geldi. Her bahar o mezarların üzerinden birer gül yeşerdi. Bu iki gül tam birbirine sarılacakken her defasında bir diken ortadan çıktı. Ve bunlar kavuşamadılar." (Ferhat ile Şirin Hikâyesi)

Âşıkların din farkından dolayı kavuşmalarının engellenmesi ise şu şekilde görülür: "Meğer Aslı dediğimiz o güzellik ve aşk abidesi, bir keşişin kızı değil miymiş! E adam da kendi çapında haklı tabi! Arada kültür farkı var. Kızımı bir Müslüman'a vermem diyip hemen o gece bütün eşyaları bir kamyonete yükledikleri gibi Samsun- Ankara otobanından tali bir istikamete sapmışlar..." (Kerem ile Aslı)

Büyü: Aslı'nın keşiş babasının büyü yapması (Kerem ile Aslı).

Dağ: Kırklar Dağı ve Suzan Suzi anlatısında görülür. akmıș."

40 sayısı: "Kırklar dağı kırk gün yas tutmuş, Dicle nehri kırk gün kırk gece gözyaşı

Çocuksuzluk: "Zengin mi zengin atları matları olan top atsan yıkılmaz bir Süryani ailenin de ne hikmetse çocuğu olmuyormuş" (Kırklar Dağı ve Suzan Suzi).

Adak: “...İşte o havalide de çocuğu olmayanlar doooğru Kırklar dağının eteğindeki Kırklar ziyaretine gidip adak adarlar "Yarabbi bizim de bir çocuğumuz olsun diye dua ederlermiş" (Kırklar Dağı ve Suzan Suzi):

“...Kiliselere mumlar mı dikmemişler, fakir fukaranın karnını mı doyurmamışlar, sabahlardan akşamlara kadar istavrozlar mı çıkarmamışlar ne yaptılar ne ettilerse bi türlü olmamış. En sonunda kadın, kocasına aman Abrahom Efendi kulun kölen olayım, 
hamama ibriğin olayım gel bi de şu Kırklar ziyaretine bi adak adayalım demiş. Ama neticede orası Müslüman ziyareti adam önceleri direnmiş sonra çocuk sevgisi ağır basmış mecburen kabul etmiş. Karı koca kırk gün kırk gece Kırklar ziyaretine kırk kurban kesmişler. Kırk birinci gün kadın hamile kalmış. Allah bu çifte nur topu gibi bir kız evlat vermiş."

“...Anneciği Suzan’ı her doğum gününde süsler püsler geydirir kuşandırır; kurdelesini, künyesini, tokasını takar Kırklar ziyaretine kurban kesmeye götürürmüş, bir nevi minnettarlık nişanesi olaraktan. Bunu adet edinmişler."

Farklı dine mensup âşıklar: Kerem ile Aslı hikâyesi; Kırklar Dağı ve Suzan Suzi hikâyesi.

Oğuz Kağan Destanı’ndaki mitolojik unsurlar: Kırk Sayısı; Altın ve gümüş; Ok ve yay; Gök, Dağ ve Deniz; Gün, Ay ve Yıldız; Gök tüylü, gök yeleli kurt; Işık; Doğunun batıdan daha kutsal oluşu; Uluğ Türk; Rüya ve rüya yorumu.

\section{Anlatılardaki Gelenek ve Görenekler:}

Görücü gönderme: “Kerem, hemen koşa koşa babasına koşar ve Aslı'yla evlenmek istediğini söyler. Biricik aslan gibi oğlunun elinde sazla müziksiyen olacağından şüphelenen, endişelenen baba, sevinir ve davullar çaldırarak, görücüler göndererek kızı istetir. Yaaa, analar ne babalar doğuruyo!"

Leyla ile Mecnun hikâyesinin anlatıldığı bölümde, Türk kültüründe bayram ve bayramlaşmanın önemini gösteren detaylara yer verilmiştir.

\section{Anlatılardaki Güncel Unsurlar:}

Anlatılarda güncel unsurlar, genellikle güldürme işlevi ile kullanılmıştır.

"Bunun üzerine Evliya Çelebi tasını, tarağını, diş fırçasını, tıraş makinasını, mavi kartını, sigorta poliçesini, okul diplomalarını ve bir de en sevdiği oyuncak ayısını bir sırt çantasına doldurmuş ve yollara revan olmuş. Devlet-i Ali-i Osmaniye'de gezmediği bir tek karış toprak kalmamış kardeşim!"

“...Nasıl aklında tutacak lan Kı1? Free Shop'tan teyp almış ona kaydetmiş."

Kerem ile Aslı Hikâyesi'nde âşıkların birbirine bir kişiyle, yazıyla, sözle haber ulaştırma geleneğinin günümüzde posta, email ya da kurye ile güncellendiği bilgisi verilir: "Aman Yarabbim! Bana bir şeyler oluyor! Kalbim hop hop ediyor, yüzümde güller açıyor! Neler oluyor bana neler oluyor?" diye Kerem'in dizinin dibine çöker ve ne mektubu beyzadem, ben sana aşkımı postayla, motorlu kuryeyle, emaille değil, bizzat dilimle beyan ederem."

Kerem ile Aslı hikâyesinde güncel unsurlar oldukça fazladır. Bu durum anlatıya mizah unsuru kattığı gibi; âşıkların kavuşamayış1, ayrı düşmesi, kavuştuğunda hasret gidermesi gibi unsurların yüzyıllar da geçse devam ettiğinin bir izdüşümü olarak değerlendirilebilir:

\footnotetext{
“Kızımı bir Müslüman'a vermem diyip hemen o gece bütün eşyaları bir kamyonete yükledikleri gibi Samsun- Ankara otobanından tali bir istikamete sapmışlar. İzlerini bir çalı süpürgesiyle silip sırra kadem basmışlar. Kerem, yana yakıla eline sazını, yanına yarenini alıp dağlarda, taşlarda, nahiyelerde, il sağlık müdürlüklerinde, devlet malzeme ofislerinde, Aslı’yı aramı1111ş, aramı111111ş, aramı1111ş. Vurrmuş sazın gözüne gözüne, saz tükenmiiiiş, dil tükenmiiiiş, yarınlar umut değil zehir olmuş. Tam umutlar tükenmişken birden Beyazıt'ta Büyük Postane'nin tam karşısındaki Elmas Büfe'de Aslı'yı jeton alırken görmüş. Hemen iki genç koşup birbirlerine sarılmışlar belediyede yıldırım nikahı yapmışlar. Balaylarını geçirmek üzere otelde rezervasyon yaptırmışlar."
}

T1kandı Baba hikâyesinde, padişahların tebdil kıyafet gezme geleneğinin günümüz insanlarınca daha rahat anlaşılabilmesi için Süpermen örneği verilir: 
“Kardeşlerim, Sultan II. Mahmud'un bir huyu varmış. Tebdil kıyafet edip, yani bi nevi Süpermen kıyafetlerini çıkarıp Clark Kent kıyafetlerini giyerek halkın arasına girer, onların hallerini, ahvallerini sual eder, onlarla dertleşir, onlarla sohbet eder, gerektiğinde bir mesele varsa anında çözermiş. İşte böyle kıyak bi padişah.”

\section{Kıssadan Hisse Bölümü:}

Ele alınan anlatıların yedi tanesinin sonunda kıssadan hisse bölümüne yer verildiği görülür. Sözlü anlatı geleneği olan meddahın icrasının sonunda öğüt verme niteliğinde kıssadan hisseye yer verdiği bilinmektedir. Bu noktada geleneksel meddahlık anlayışını Heredot Cevdet'in devam ettirdiğini söylemek mümkündür:

"Ey gülün dikeni be! Ne gül olmak kolay ne de gül olmak! Bülbül olmayı seçtiysen bir ömüüüür yanacaksın. Gül olmayı seçtiysen bir ömüüür solacaksın.” (Bülbülün Hikâyesi)

Kimi zaman Kıl'ın sorularına Heredot Cevdet'in de verebilecek bir cevabı olmaz. Böyle durumlarda "işin ehli"ne müracaat edilir ve anlatının kıssadan hisse bölümü Nusrettin Baba tarafindan dile getirilir:

"Nusrettin Baba: "Karınca âşık olmuş, dağların ardındaki sevdiğine kavuşabilmek için yollara düşmüş. Etraftan yav sen küçücük bir karıncasın. Boyun ne bosun ne? Onlarca yolu aşıp da sevdiğine kavuşamayacağını bile bile ne diye gidiyosun? Demişler. Sevdalı karınca da hiç bana karışmayın, kavuşamasam da yolunda ölürüm ya!" (Ferhat ile Şirin)

Orhun Kitabeleri’nin neden parşömene, kâğıda yazılmayıp taşa yazıldığına Nusrettin Baba'nın verdiği cevap: “Taş taşımak, laf taşımamak için” olmuştur. (Köktürk Yazıtları) Bu söz de anlatının kissadan hissesini bize verir.

Kerem ile Aslı hikâyesinde Kı1, "İyi de Aga biz ne zaman böyle âş1k olucaz?" diye sorar. Heredot Cevdet'in cevabı anlatının kıssadan hissesi niteliğindedir:" Kafana bir şey takılmayınca Kıl Efendi, gönlüne takılınca!“‘

Kırklar Dağı ve Suzan Suzi anlatısının sonunda, Celal Heredot'a soru sorar. Heredot, Celal'in âşık olduğunu bilir. "Sorunu âşık olan bilir, biz bilmeyiz. Var mı aranızda âşı olan" der. Cevap gelmeyince Celal, ben ehline başvurayım diyerek Nusrettin Baba'nın yanına gider. Baba'nın cevab1, hem anlatı için hem de Celal için kıssadan hisse niteliğindedir: "Sana, seni gerek Celal'im. Seni! Beni değil! Allah mutlu etsin!"

"Kardeşlerim! Sevelim, sevilelim, sevenleri ayırmayalım! Bu dünya kimseye kalmıyor!“ (Leyla ile Mecnun)

"Kı1: İyi de Aga, kafama takıldı. Sultan Mahmud neden bizzat para vermemiş de böyle yan yolları denemiş?

Heredot Cevdet: Ulan Kılbey, Vermeyince Mabud Neylesin Sultan Mahmud?" Tikandı Baba hikâyesinin sonunda, hikâyenin kıssadan hissesi olarak verilmiştir.

\section{Dua Bölümü:}

Ele alınan anlatılarda genellikle aşk hikâyelerinin sonunda dua bölümüne yer verildiği görülür. Dinleyicilerin de böyle hakiki aşk yaşamaları; ölen âşıkların mekânlarının cennet olması dileği belirtilir.

\section{"Âşıkların mekânı Cennet olsun. Amin.” (Ferhat ile Şirin)}

"Leyla, elveda zalim insanlar, elveda zalim dünya, elveda bizi evermeyenler! Ben Mecnunum'a kavuşuyorum! diye diye diye Hakk'ın rahmetine kavuşur! Mekânı Cennet olsun!” (Leyla il Mecnun) 
Yusuf ile Züleyha hikâyesi de "Yusuf ile Züleyha, öbür dünyada aşklarını ebediyen yaşamak üzere son nefeslerine kadar birbirlerini sevmişler. Bütün hakiki sevenlere böyle bir aşk nasip olsun. Aaamin!“‘ şeklinde dua ile biter.

\section{Sonuç}

Ekmek Teknesi dizisindeki Heredot Cevdet anlatıların icracısıdır ve herkes tarafından bilgeliği ile tanınır, kendisine saygı duyulur. Tarihçi Heredot'un ve sentezciliği ile bilinen Ahmet Cevdet Paşa'nın karışımı olarak ortaya çıkar. Bu özelliği inandırıcılığını da kolaylaştırmaktadır.

Anlatılardaki mekânın kahvehane olması ve zamanın akşam saatleri olması yönüyle de geleneksel meddahlığa benzemektedir.

Meddahların aksesuarları genellikle sandalye, baston veya sopa, mendil veya makramedir. Heredot Cevdet de kahvehaneye girince sandalyeye oturmaktadır. Dikkati toplamak için çay bardağını üç defa masaya vurmaktadır. Çay bardağı anlatıda sopa görevini görmektedir.

Dil ve üslup açısından anlatılara bakıldığında meddahın hikâye anlatırken kullandığı tekerlemeler, ikilemeler, söz sanatları, taklitler ve benzetmelerin Heredot Cevdet'te de kullanıldığ görülür. Ayrıca bilmece de yer almaktadır. Özellikle mübalağa sanatı inandırıcıllğa katkı sağlama ve dikkati toplama amacıyla çok fazla kullanılmıştır.

Heredot Cevdet anlatılara başlarken anlatıyla ilgili ipucunu laf arasında vermektedir. Cümleler arası geçişleri ve konu içinde bilgilendirmeyi oldukça ustaca yapmaktadır. Bu da bir meddahta olan en önemli özelliklerden biridir.

Zaman kavramı kapsamında masallardaki gibi anlatımlar da görülmektedir. Anlatılarda öğüt verici sözler de kullanılmıştır. Heyecan anlatı boyunca hem Heredot Cevdet'in sesini yükseltmesi hem de Ölü karakterinin "Allah" diye bağırışı ile canlı tutulmuştur.

Rüya, âşıkların kavuşamaması, büyü, dağ, kırk sayısı, çocuksuzluk, adak, farklı dine mensup âşıklar; Oğuz Kağan Destanı anlatımındaki kırk sayısı, altın ve gümüş, ok ve yay, gök, dağ ve deniz, gün, ay ve yıldız, gök tüylü, gök yeleli kurt, 1şık, doğunun batıdan daha kutsal oluşu tespit edilen motifler ve mitolojik unsurlardır.

Anlatılardaki görücü gönderme ve bayramlaşma Türk gelenek ve göreneklerinden örnekler olarak yer almaktadır.

Anlatılarda güncel unsurlar, genellikle güldürme işlevi ile kullanılmıştır. Evliya Çelebi'nin tasını, tarağını, diş firçasını, tıraş makinasını, mavi kartını, sigorta poliçesini, okul diplomalarını ve bir de en sevdiği oyuncak ayısını bir sırt çantasına doldurup yollara revan olması, Free Shop'tan teyp alması; Kerem ile Aslı Hikâyesi'nde âşıkların birbirine posta, email ya da kurye ile haber ulaştırması, eşyaların kamyonete yüklenmesi ve İstanbul mekânlarının söylenmesi; Tıkandı Baba hikâyesinde Sultan II. Mahmud'un bir nevi Süpermen kıyafetlerini çıkarıp Clark Kent kıyafetlerini giyerek halkın arasına girmesi güncelleştirilmiş unsurlar olarak karşımıza çıkmaktadır.

İncelenen anlatıların yedi tanesinin sonunda kıssadan hisse bölümüne yer verilmiştir. Sözlü anlatı geleneği olan meddahın icrasının sonunda öğüt verme niteliğinde kıssadan hisseye yer verilmektedir. Anlatılarda genellikle aşk hikâyelerinin sonunda dua bölümüne de yer verilmiştir.

Heredot Cevdet anlatılarındaki tespit edilen özelliklere bakıldığında, anlatılar geleneksel meddahlığın medyada görülen güncelleştirilmiş anlatımı şeklinde değerlendirilebilir. $\mathrm{Bu}$ açıdan bakıldığında anlatılar eğitim ortamında da kullanılabilir. almaktadır:

Ortaöğretim Türk Dili ve Edebiyatı öğretim programında tiyatro türünde şu kazanımlar yer

"Metnin türünün ortaya çıkışı ve tarihsel dönemle ilişkisini belirler. 
a. Metin türlerinin ortaya çıkmasında sözlü ve yazılı kültürün, toplumsal değişimlerin ve etkileşimlerin, teknolojinin etkisi üzerinde durulur.

b. Geleneksel tiyatro (Karagöz, orta oyunu, meddah, köy seyirlik oyunları) ve tiyatro türleri (trajedi, komedi, dram) ile senaryodan bahsedilir. (s. 23)

Öğretim programında şu açıklamalar da yer almaktadır:

“A.3. 13. Türün ve dönemin/akımın diğer önemli yazarlarını ve eserlerini sıralar.

a. Önde gelen, temsil edici diğer yazar ve eserlerden bahsedilir.

b. Geleneksel tiyatroda ise kalıplaşmış ünlü oyunlara (Örnek: Kanlı Nigâr) ve ünlü meddah, kavuklu, pişekâr ve Karagözcülere (Kel Hasan, Abdürrezzak, İsmail Dümbüllü vs.) değinilir.

c. Türün ve dönemin/akımın diğer önemli yazar ve eserleri 10,11 ve 12 . sınıf düzeylerinde ele alınacaktır.” (TDEÖP: 24).

10. sınıf, 6. ünite tiyatro türünde sözlü iletişim bölümünde "Meddah hakkında bilgi verilir. Öğrencilerin izledikleri birer meddah ve stand-up gösterisinden hareketle kısa bir meddah oyunu sunmaları sağlanır. Genel Ağ'dan Karagöz oyunu videoları izlenir." (TDEÖP: 44) açıklaması yer almaktadır.

$\mathrm{Bu}$ kazanımlar ve açıklamalar doğrultusunda Heredot Cevdet de Türk Dili ve Edebiyatı dersinde örnek olarak kullanılabilir. Böylece öğrenciler bu türleri daha iyi öğrenebilirler ve bu kullanımlar geleneğin devam etmesinde olumlu etki oluşturabilir.

Yapılan incelemeler sonucunda şu öneriler geliştirilmiştir:

1. Türk Dili ve Edebiyatı öğretiminde geleneğin güncelleştirilmiş örneklerine, öğrenciyaşantı bağ 1 kurma bağlamında daha fazla yer verilebilir.

2. Meddahlık geleneği ile başka elektronik anlatılar da incelenip eğitim ortamına kazandırılabilir.

\section{Kaynakça}

And, M. (2006). Meddah, meddahlık, meddahlar. Ü. Oral (Hzl), Meddah Kitabı (ss. 3-17). Kitabevi Yayınları.

Ataman, S.Y. (1974). Dümbüllü İsmail Efendi. Yapı Kredi.

Bars, M. E. (2019). Türk Anlatı Geleneğinde Anlatıcı Merkezli Değişim/Dönüşüm: Geleneksel Hikâyecilerden Medyatik Hikâyecilere. Motif Akademi Halkbilimi Dergisi, 12, 25, 1-20. https://doi.org/10.12981/mahder.512496

Boratav, P. N. (2002). Halk hikâyeleri ve halk hikâyeciliği. Tarih Vakfı Yayınları.

Devellioğlu, F. (2004). Osmanlıca-Türkçe ansiklopedik lügat. Aydın Kitabevi.

Durmaz, U. (2018). Geleneksel Türk Tiyatrosunda "Kavuk": Bir Simgenin İşlevi, Özellikleri, Temsilcileri ve Dünden Bugüne Yolculuğu. Uluslarası Beşeri Bilimler ve Ĕgitim Dergisi, 4(9), 13-47.

Gerçek, S. N. (2006). Meddah. Ü. Oral (Hzl), Meddah Kitabı (ss. 18-22). Kitabevi Yayınları.

Hürriyet Gazetesi (2016). Kavuğun yeni sahibi belli oldu. http://www.hurriyet.com.tr/kelebek/keyif/kavugun-yeni-sahibi-belli-oldu-40103194 
Kaim, A. (2006). Sözlü Edebiyat Ve Gösteri Kültürü Buluşma Noktası: Meddah Tek Kişilik Tiyatro. Ankara Üniversitesi Dil ve Tarih-Coğrafya Fakültesi Dergisi, 46 (1), 271-282. https://doi.org/10.1501/dtcfder_0000001027

Kaim, A. A. (2010). Meddah Geleneğinden Kültürlerarası Hikâyeciliğe Uzanan Bir Serüven. Tiyatro Araştırmalarl Dergisi, 30(2010/2), 111-122. https://doi.org/10.1501/tad_0000000254

Kaya, D. (2010). Türk halk edebiyatı terimleri sözlüğü. Akçağ Yayınları.

Korkmaz, D. (2019). Tek kişilik oyunlar. Yayımlanmamış Yüksel Lisans Tezi, Hacettepe Üniversitesi Sosyal Bilimler Enstitüsü, Ankara.

Köprülü, M. F. (2012). Türklerde halk hikâyeciliğine ait maddeler meddahlar. Edebiyat araştırmaları I (5. basım, ss. 317-356). Akçağ Yayınları.

Kudret, C. (1995). Örnekli Türk edebiyatı tarihi. Kültür Bakanlığı, Başbakanlık Basımevi.

Nutku, Ö. (2006). Meddahlık olgusu. Ü. Oral (Hzl), Meddah Kitabı (ss. 30-56). Kitabevi Yayınları.

Ong, Walter J. (2003). Sözlü ve yazılı kültür: sözün teknolojileşmesi. S. Postacioğlu Banon (Çev.) Metis Yayınları. https://doi.org/10.7827/turkishstudies.12319

Oklay, E. (2014). Ahmet Cevdet Paşa'nın Türk Eğitim Tarihi Açısından Önemi Üzerine Bir İnceleme. Tarih Incelemeleri Dergisi, XXIX/1, 233-251. https://doi.org/10.18513/egetid.69168

Komisyon (2019). Ortaöğretim Türk dili ve edebiyatı dersi ögretim programı. MEB.

Sekmen, M. (2008). Meddah ve gösterisi, Anadolu Üniversitesi Yayınları.

Yıldırım, A. ve Şimşek, H. (2013). Sosyal bilimlerde nitel araştırma yöntemleri. Seçkin Yayıncılık. 